\title{
University Cogeneration Initiative as a Class Project Opportunity
}

\author{
Mary Kathryn Mathis, Ahad S. Nasab, Duane Stucky \\ Middle Tennessee State University
}

\section{Introduction}

Energy management and budgeting has long been a major concern of academic institutions which usually operate on a shrinking operations budget and a generally rising demand due to increase in student enrollment and addition of new buildings and facilities and laboratories.

In recent decades cogeneration has been looked upon as one way of managing the energy costs as well as replacing older technology with the more environmentally-friendly hardware. Like many other systems, decision on such a major investment depends on rate of return and market forecast of utility price fluctuations.

\section{Cogeneration system}

Cogeneration systems installed on university campuses usually generate a portion of the total electric consumption with the exhaust heat used in bottoming cycles to provide other effects such cooling through the use of chillers.

The existing system at MTSU is comprised of a coal-fired plant which is used for winter heating as well as summer cooling through the use of chillers. The university was faced several problems with regards to the existing plant such as obsolescence of the components, lack of pollution control equipment to comply with upcoming EPA standards, and inadequate reserve capacity

For the last two years, the administrative staff of the Middle Tennessee State University with the annual enrollment of nearly 18,000 students have taken on the task of studying the feasibility of a cogeneration system for this campus. An energy consulting firm was hired to examine the concept of installing a gas turbine and generator to produce about half the campus electrical needs with the waste heat from the turbine to produce steam needed for campus buildings heating and cooling needs. Preliminary analysis has shown that the proposed cogeneration system will pay for itself in savings in about ten years. The new plant has the advantage of being much more efficient and environmentallyfriendly than the existing plant as well as being able to serve the campus energy needs for the foreseeable future. A schematic of the MTSU cogeneration system is shown in Figure 1.

\section{Student Involvement}

Students enrolled in several environmental science classes at MTSU have the unique opportunity to be involved in a sizable university project in which an existing steam generation plant is being replaced by a modern cogeneration facility. Students associated with the project work very closely with the engineers and administrators to 
get first-hand experience of technical, administrative, and economical aspects of a reallife project.

Students work in teams of two or three members in one the following areas;

1. Administration and Planning

2. Engineering and Design

3. State and Federal Regulations

4. Maintenance and Service Contracts

Each team is encouraged to work closely with the project staff to gather information and in some cases contribute to the project.

The Administration and Planning team consults with the university administration officers and other project staff to investigate the overall criteria for investment decisions and budget issues. These activities usually involve comparison of the proposed system to other traditional systems in several respects such as cost analysis, depreciation issues, regulatory issues, local government and utilities issues, and overall university facility needs analysis.

The Engineering and Design group is given a certain input such as fuel grade and quality, space and cost constraints and are asked to propose or specify a cogeneration system which will comply with the university energy and other needs. This group must have, early in the project, some overall numbers from the Administration and Planning team. The members in the engineering team consult with the staff engineers to justify the specified equipment and operation modes. This activity not only involves thermodynamic and heat transfer analysis, but also encompasses areas such as energy auditing and energy quality.

Issues such as pollution control and related hardware and practices are looked at by the State and Federal Regulation team. This team will serve as the expert group in the current codes and regulations and will provide input to the first two teams in pollution control matters. The areas of pollution involves all aspects of gaseous and particulate exhaust as well as noise generated by the gas turbine generators.

One of the most important steps in implementing a successful project is to have a thorough and suitable maintenance plan for the installed system. Issues concerning the maintenance contracts and periods are studied by the Maintenance and Service Contract team. This team initially studies previous service contracts between the university and various service providers and by interviewing the university staff determines the factors that contribute to a successful and adequate service contract. Then the team tries to implement those findings in the items of the future service contracts for the cogeneration plan. 
Students participating in the activities listed above are provided the rare opportunity to witness a major on-going university project and be involved in many aspects of the project. The students appreciate many facets of the project and realize that any sizable project includes much more than mere engineering and economic analysis. Findings of each group is discussed in class sessions to inform all the group members and provide routine progress reports.

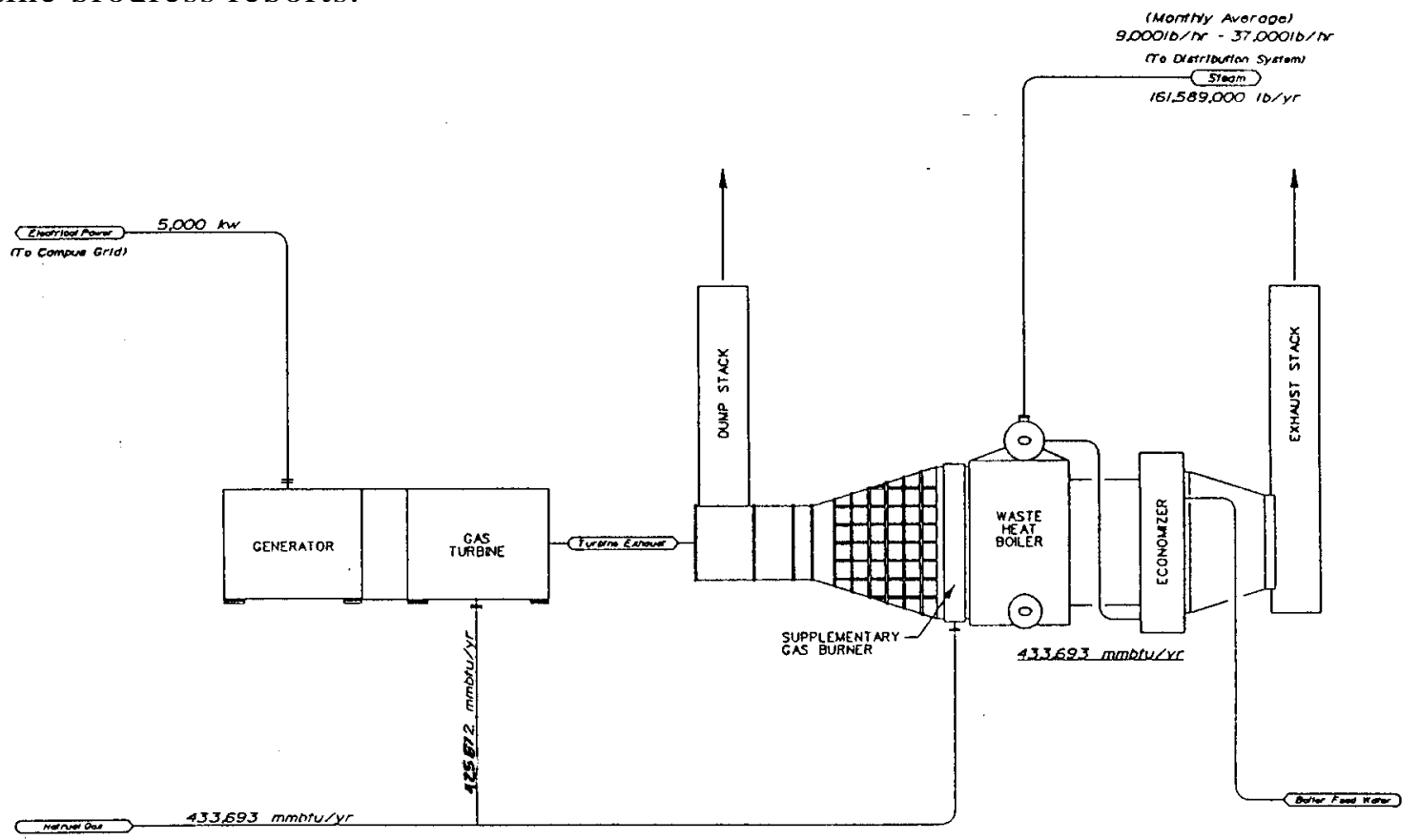

Figure 1: Schematic of the MTSU 5 MW gas-fired co-generation plant

1. "Comprehensive Energy Management Performance Services and Utility Master Planning ", Facilities Resource Management Co., Oct. 21, 1992.

2. "MTSU Co-generation System", I.C. Thomasson Associates, Inc., a report submitted to MTSU, March 27, 1995.

MARY KATHRYN MATHIS is the coordinator of the environmental science and technology program at Middle Tennessee State University. She has been a consultant in the area of solar building design and energy efficient homes. She is a member of the technical committee at MTSU which is responsible for the implementation of the new gas-fired co-generation plant.

AHAD S. NASAB received his doctorate degree in mechanical engineering from Georgia Institute of Technology in 1987. He has since been involved in laser and plasma propulsion systems research sponsored by AFOSR, ARMY, NASA, and NSF. He has recently been coordinating the electromechanical engineering technology program at Middle Tennessee State University.

DUANE STUCKY received his doctorate in mechanical engineering. He has taught engineering courses throughout his career and has served as vice president of finance and administration at several universities. He oversaw the expansion of a 55 megawatt, coal-fired co-generation plant at the University of Missouri, and initiated the design of a gas-fired co-generation plant at Middle Tennessee State University on which construction will begin later this year. 